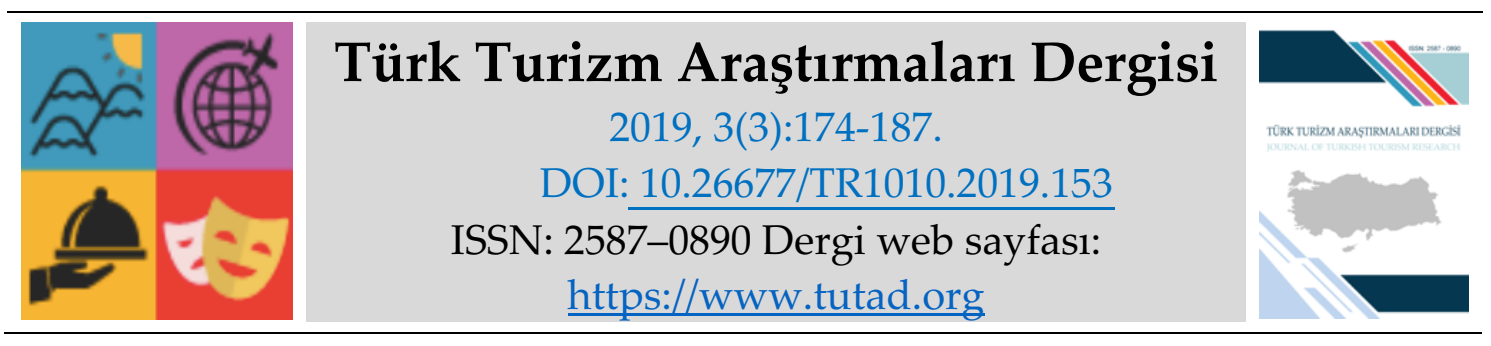

ARAȘTIRMA MAKALESI

\title{
Çevrimiçi Platformların Konaklama Sektörüne Etkileri
}

Doç. Dr. Rıdvan KOZAK, Anadolu Üniversitesi, Turizm Fakültesi, e-posta: rkozak@anadolu.edu.tr ORCID: https://orcid.org/0000-0001-5846-0489

Dr. Can Cemal CiNGİ, Anadolu Üniversitesi, İletişim Bilimleri Fakültesi, e-posta: ccc@anadolu.edu.tr

ORCID: https://orcid.org/0000-0002-1769-3435

Öz

Online/Çevrimiçi Seyahat Acentaları (OTA'lar), çevrimiçi rezervasyon olanakları sağlayan dijital platformlardır. Onlar otel rezervasyonlarının büyük bir bölümüne hâkimdir. Özellikle bağımsız oteller OTA'lara bağımlı hale gelmiştir. Sektör yüksek komisyonlardan şikâyetçi durumdadır. Türkiye G20 ülkesi içinde Platform Hazırlık Endeksi Sıralamasında son sıralardadır. Buna karşın, pazarı olgunlaştıracak girişimlerde bulunarak, komisyonsuz gelir modeline dayalı platform ekosistemleri hayata geçirebilir. Model önerilerine geçmeden önce, bu çalışma tüketicilerin internetteki arama davranışlarına odaklanmış ve araştırmada veri toplama yöntemi olarak odak grup görüşmesi kullanılmıştır. Bulgulara göre, OTA tercihlerinde ilk sırayı Booking.com, Metasearch uygulaması olarak ilk sırayı Trivago almaktadır. Araştırmaya katılanların yarısı ise otel ararken öncelikle arama motoru kullanmaktadır. Netice olarak komisyonsuz ekosistemler yaratırken, arama motorlarının ilk sayfasında ve organik sıralaması içinde yer almayı başarmak gerekmektedir.

Anahtar Kelimeler: İnternet, OTA, Web, Konaklama, Turizm

Makale Gönderme Tarihi: 17.01.2019

Makale Kabul Tarihi: 01.07.2019

\section{Önerilen Atıf:}

Kozak, R. ve Cingi, C. C. (2019). Çevrimiçi Platformların Konaklama Sektörüne Etkileri, Türk Turizm Araştırmaları Dergisi, 3(3): 174-187.

(C) 2019 Türk Turizm Araştırmaları Dergisi. 


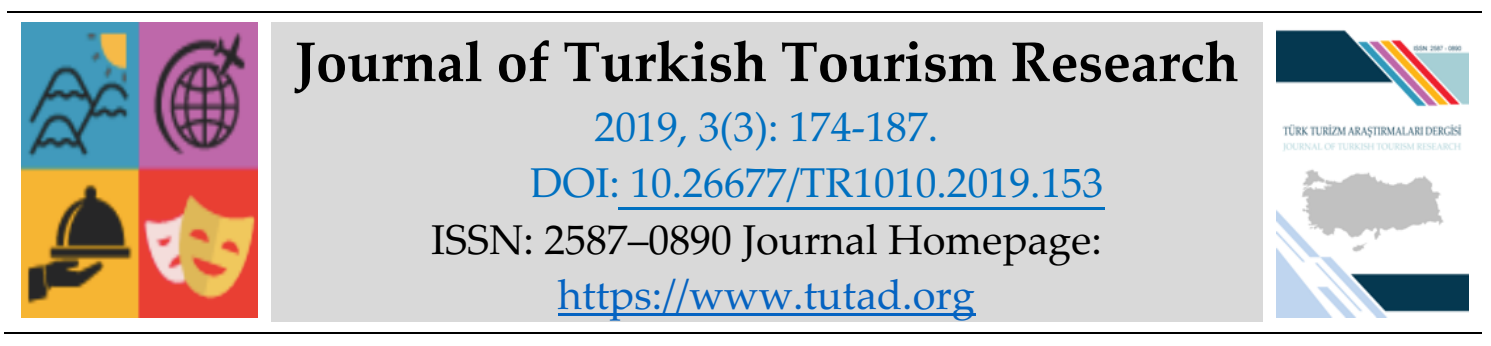

\title{
RESEARCH PAPER
}

\section{The Effects of Online Platforms to the Accommodation Sector}

Ass. Prof. Dr. Rıdvan KOZAK, Anadolu University, Tourism Faculty, e-mail: rkozak@anadolu.edu.tr ORCID: https://orcid.org/0000-0001-5846-0489

Dr. Can Cemal CiNGİ, Anadolu University, Faculty of Communication Sciences, e-mail: ccc@anadolu.edu.tr

ORCID: https://orcid.org/0000-0002-1769-3435

\begin{abstract}
Online/Online Travel Agencies (OTAs) are digital platforms that provide online booking opportunities. They dominate most of the hotel bookings. Especially independent hotels have become dependent on OTAs. The sector is complaining about high commissions. Turkey is at the last place in the rankings of the G20 countries Platform Readiness Index. On the other hand, it can implement platform ecosystems based on commission-free income model by making initiatives to mature the market. Prior to model recommendations, this study focused on consumers' search behavior on the Internet and focus group interview was used as the data collection method in the study. According to the findings, the first place in the OTA preferences as Booking.com, the first place as Metasearch Trivago takes. Half of the respondents searched the hotel for a search engine. As a result, when creating platform ecosystems without commissions, it is necessary to succeed in the first page of the search engines and in the organic order.
\end{abstract}

Keywords: Internet, OTA, Web, Accommodation, Tourism

Received: 17.01.2019

Accepted: 01.07.2019

\section{Suggested Citation:}

Kozak, R. and Cingi, C. C. (2019). The Effects of Online Platforms to the Accommodation Sector, Journal of Turkish Tourism Research, 3(3): 174-187.

(c) 2019 Türk Turizm Araştırmaları Dergisi. 


\section{Gíriş}

Yirmi birinci yüzyılın hemen başlarında, konaklama endüstrisini sonsuza dek yeniden şekillendirecek, yaygın olarak Online/Çevrimiçi Seyahat Acentaları veya OTA'lar olarak adlandırılan, otel odalarını internet üzerinden kolayca satılmalarını sağlayan Expedia, Travelocity ve Orbitz gibi web siteleri, başka bir ifadeyle dijital platformlar hayata geçirilmiştir. Hızla büyüyerek çevrimiçi rezervasyon pazarında büyük paylar elde etmiş, Booking.com ve Ctrip.com gibi platformlar büyük sayıda kendilerine sadık üye hacimlerine ulaşmışlardır. OTA'lar geleneksel otel markalarının ötesinde değerlenmiş, örneğin Mayıs 2017 itibariyle, Priceline Grubu yaklaşık 92 Milyar ABD Doları değerine erişmiştir. Zamanla muazzam bir şekilde büyüyen OTA'lar sayesinde dünyadaki hemen hemen her otel için gerçek zamanlı fiyatlara ve müsaitlik durumuna da erişilir olmuştur (Cohen, 2017). Bu yapı kendini korurken, 'Meta Arama' kanallarının da hızlı bir şekilde genişlediği görülmektedir. Bunlar, bir müşterinin tek bir otel odası için fiyatı birden fazla web sitesinde (bu web sitelerine göz atmak zorunda kalmadan) görüntüleyebildikleri tek noktadan fiyat karşılaştırma platformlarıdır. Bu kategorideki siteler, Kayak, Trivago, TripAdvisor, Qunar ve Google olarak sayılabilir. Hepsi tüketicilerin seyahat araştırma sürecini basitleştirmek için çalışmaktadır (Cohen, 2017.)

Sıkça kullanılan 'çevrimiçi platformlar' terimi, internet üzerinde iki veya daha fazla farklı kullanıcı grubu için buluşma yeri sağlayan dijital işlerin geniş bir kategorisini tanımlamaktadır. Örnekler arasında arama motorları, çevrimiçi pazarlar, işbirlikçi veya paylaşımcı ekonomi ve sosyal ağlar sayılabilir (HL, 2016: 7). Avrupa Komisyonunun 2017 tarihli raporunda, Amazon ve Booking.com gibi uygulamaları "Pazar Yerleri (Marketplaces"), Google Play ve Apple App'i "Uygulama Mağazaları (App stores)", Facebook ve Instagram'1 "Sosyal Ağlar (Social networks)", Doubleclick gibi uygulamaları ise "Çevrimiçi Reklam (Online advertisement)" platformları şeklinde dört farklı platform olarak örneklendirmiştir (European Union, 2017). Avrupa Birliği bir başka raporunda ise, arama motorları ve sosyal ağlardan, fiyat karşılaştırma web sitelerine ve işbirlikçi ekonomi platformlarına kadar çok çeşitli yazılım tabanlı teknolojilerden oluşan çevrimiçi platformları, inovasyon, rekabet ve büyümenin temel sürükleyicileri olduğunun altını çizmektedir. Onların, dijital ekonominin yarattı̆̆ fırsatlardan işletmelerin ve tüketicilerin en iyi şekilde yararlanmasına hizmet ettiğine işaret edilmektedir (HL, 2016: 4). Diğer bir raporunda, çevrimiçi platformların KOBİler için büyük bir sınır-ötesi pazar fırsatı sunmakta olduğu belirtilmektedir. Firmaların platformlar ile karşılaştığı başlıca sorunlara ilişkin olarak ise, platformların belirlemiş olduğu "Şartlar ve Koşullar" da ani ve açıklanamayan değişiklikler yapması ilk sırada yer aldığı ifade edilmektedir (T.C. Ticaret Bakanlığı, 2018).

Diğer yandan platform ekosisteminden bahsederken, Türkiye'nin içinde bulunduğu uygun ortam ve kritik kitleyi oluşturma gibi iki kilit platform faktörü zorluklarına burada yer vermek gerekir. Türkiye, Platform Hazırlık Endeksi Sıralamasında yer alan 16 G20 ülkesinden 13. Sırada yer almakta ve 2020 yılına kadar bu konumda kalması beklenmektedir (Accenture, 2018). Dijital popülasyonun ve pazarın olgunluğunu büyüklüğe, tasarrufa, kültüre ve iş birliğine dayalı inovasyon ruhuna göre ölçen Accenture'ın Platform Hazırlık Endeksi, G20 ülkelerini dijital platformun benimsenmesi için uygun bir ortam yaratan etkenler konusunda karşılaştırma yapmaktadır. Ülkenin endeksteki yerine bakıldığında, yüksek sayıda dijital platforma ev sahipliği yapıyor olmasına rağmen, ekosistem açısından iyi bir görüntü vermemektedir. Öyleyse ülke için platform yolculuğu tam anlamıyla başlamamış demektir.

Günümüzde görülen o ki, yoğun küresel rekabet ölçeğinde konaklama işletmeleri internette daha etkin var olmak isterken, mevcut platformlar üzerinden daha fazla satış yapmakta ancak daha 
yüksek komisyonlar ödemeye razı olup, yüksek maliyetlere katlanmak durumuna gelmişlerdir. Oysa literatürde, konaklama işletmelerinin müşterileriyle doğrudan iletişim ve etkileşiminde internetin olumlu yönde etkisinin olduğu sıkça vurgulanmaktadır. Özellikle büyük otel işletmelerinin doğrudan satış yolunu tercih etmesinin dağıtım kanalı olarak seyahat acentalerinin rollerini bile sarsacak güçte olduğu ifade edilmektedir (Chingbiu, 2003). Ayrıca turizm pazarında tedarikçilerin tüketiciler ile doğrudan iletişim kurmak için web sitelerine sahip oldukları belirtilmektedir (Kracht ve Wang, 2010). Günümüzde neredeyse tüm konaklama tesisleri birer web sitesine sahip olmasına rağmen onların çevrimiçi doğrudan rezervasyon ve satışa yönelik fonksiyonlara sahip bulunmadığı, statik tasarım yapı sergiledikleri görülmektedir. Konaklama işletmelerinin web sitesi üzerinden pazarlama ve e-ticaret faaliyetlerine yeterince önem vermedikleri ve web sitelerini tanıtım amaçlı kullandıkları anlaşılmaktadır (Ateş ve Boz, 2015).

Bu çalışma, konaklama işletmelerinin internette etkin var olma sorunları ve çözümün tüketiciye direkt satış başarısının geliştirilmesine bağlı olduğuna dikkat çekmekte ve bu yönde öneriler ortaya koymayı amaçlamaktadır. Öncelikle internet kullanıcılarının OTA'lara yönlenmesine ve oradan rezervasyon ve satın almalarına etki eden davranışları tanımlamak gerekir. Bunları; tüketicilerin internette (öğrenilmiş) arama davranışları, çevrimiçi aracıların internette konumlanma davranışları ve arama motorlarının çalışma davranışları olarak üç boyutta ele almak mümkündür. Bu noktadan hareketle tesislerinin direkt satış başarısına çözümler geliştirilebilir. Müşterilere ulaşmak için bu günkü komisyonlu platformlara kendini mahkûm hisseden küçük ve orta ölçekli (KOBİler) veya mikro işletmeler için bu sorunun aşılmasında platform kooperatifçiliği gibi bir yaklaşım sektör için iyi bir model olarak önerilebilir. Ancak ne var ki, pazarlama aşamasında güven, uzun vadeli bir ilişkinin başlatılması, geliştirilmesi ve sürdürülmesinde önemli bir faktördür. Güven müşteri sadakatine ve bağlllı̆̆ına yol açar, risk algısını, belirsizliği, çatışmayı ve fırsatçı faaliyetleri azaltır (Morgan ve Hunt, 1994; Bowen ve Shoemaker, 1998; Garbarino ve Johnson, 1999). Ayrıca tüketicilerin belirli bir işlemi değerlendirmesi olarak ifade edilen (Bolton ve Drew,1991) tüketici memnuniyetinin de iş süreçlerinin her aşamasında dikkate alınması gerekir.

\section{INTERNETTE TURİM VE ARACILAR}

İnternetin karar ve iş süreçlerini önemli ölçüde kısalttığı bir gerçektir. Geleneksel araçlara göre daha kapsamlı bir içerik sunarak turistik tüketicinin beklentileri ile deneyimi arasındaki farkı azaltan internet, kötü sürprizleri de ortadan kaldırır (Algür, Ömüriş ve Erdoğan, 2006). Turizm ürününün hizmet yoğunluklu niteliğine bağlı olarak satın alım öncesi detaylı ve doğru bilgilenmeyi istemek doğaldır. Bu noktadan bakıldığında bilgi ve iletişim teknolojilerinin turizmdeki önemi öne çıkmaktadır (Algür, 2007). Fiziksel ürünler üreten sanayi işletmelerine göre soyut hizmetler üreten turizm işletmeleri için pazarlama faaliyetleri daha karmaşık özelliklere sahip olduğundan söz konusu ürünler ve hizmetler etkin bir şekilde pazarlanamadığ 1 takdirde doğal olarak satışları da istenen düzeyde olamayacaktır (Zengin ve Şen, 2006).

Dünya Turizm Örgütü'nün 2023 tahminlerinden anlaşılacağı gibi, rezervasyon süreçlerinde elektronik teknolojilerinin önemi gittikçe artacaktır (Emir, 2016). Bilgi teknolojileri ve küreselleşmenin beraberinde getirdiği değişimlerden tüm işletmeler etkilenmeye devam edecektir. Aşağıdaki Şekil 1, seyahat dağıtım zincirinin tedarikten talebe olan basit bir görünümünü sunmaktadır. Zincirdeki her bir bağlantı, zincirin diğer elemanları ile etkileşime girebilirler. Şekilden anlaşılacağı gibi tedarikçiler, tur operatörlerine ve perakendecilere satış yapabilecekleri gibi, doğrudan tüketicilere de satış yapabilir (ETTSA, 2010). 


\section{Seyahat Dağıtım Zinciri}

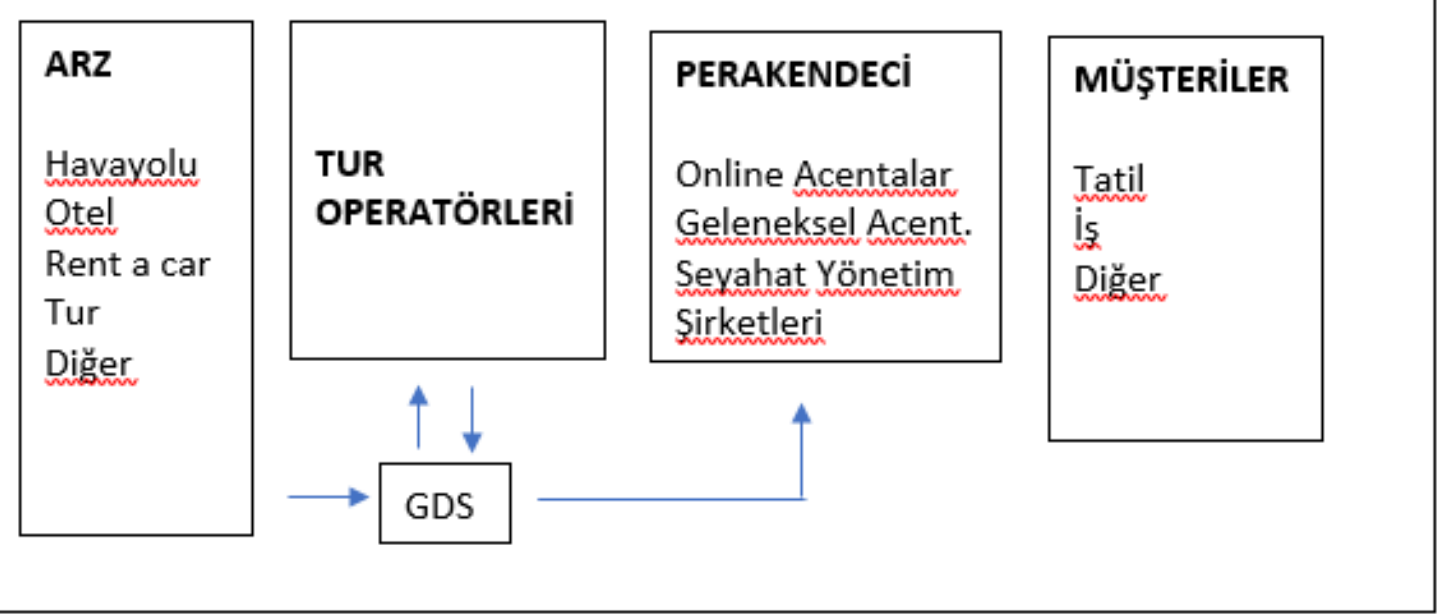

Şekil 1. Arzdan Talebe Seyahat Dağıtım Zinciri

Geleneksel dağıtım sisteminin hala kullanılmasına karşın internete dayalı dağıtım sisteminin hızla büyüdügünü acıktır (Law vd., 2015). Büyümenin nedenlerine yönelik yapılan bir çalışmada, "kullanıcı yorumları" ve "fiyat karşılaştırabilme" olanakları öne çıkan unsurlar olarak ortaya konmuştur (Keskinkılıç, Ağca ve Karaman, 2016).

Günümüzde gerçekten tüm konaklama işletmeleri bir şekilde internet ortamında yer almakta, neredeyse tamamı bir web sitesine sahip ve/veya dijital platformlarda (OTA, Metasearch, Search Engine) bulunmaktadır. Dijital platformlar, karmaşık yazılım, donanım, işlem ve ağ karışımlarıdır. Temel yapısı, istikrarlı bir zemin üzerinde istediklerini inşa edebilecek geniş bir kullanıcı grubuna bir dizi ortak teknik, teknoloji ve ara yüz sunmalarıdır (Kenney ve Zysman, 2016). OTA'lar, "oteller, havayolları, araç ve diğer hizmetler için kullanıcılara seyahatle ilgili çevrimiçi rezervasyon olanakları sağlayan seyahat web siteleri"dir ve çevrimiçi otel odaları rezervasyonlarının büyük bir bölümüne hâkimdir (Morales, 2017: 10). Bağımsız oteller özellikle OTA'lara bağımlıdır. Ortalama olarak, bağımsız otel rezervasyonlarının \%76'sı OTA'lar dan yapilmaktadır (Luebke, 2017).

Seyahat pazarında tüketicilere tek kanalda birden fazla seyahatle ilgili hizmet sağlayan OTA'lar, tahmini satış rakamlarında yıllık \%12 büyüme ile seyahat endüstrisindeki en güçlü oyunculardan biri haline gelmişlerdir. (Forbes, 2015). Marvel'e (2016) göre, büyük otel zincirlerinin toplam rezervasyonlarının yaklaşık \%10'u OTA'lara bağlıyken bağımsız bir otel için bu oran \%70'e dayanmış durumdadır. Bu nedenle, platformların endüstrideki önemini ve yerini anlamak, doğrudan kendi web sitelerinden rezervasyon almaya çalışan oteller için stratejiktir. OTÁların büyüyen hâkimiyeti, doğrudan rezervasyon olasılığına karşı en büyük tehdittir.

Morales'in (2017) çalışmasında ortaya konulduğu gibi, piyasadaki en büyük OTA, 88 milyar dolarlık piyasa değeri ile Avrupa Birliği'nin \%62'sini kontrol eden Priceline grubudur. TripAdvisor.com, Expedia ve Priceline Grubu seyahat endüstrisindeki aktif OTA'lardır. Rovia, 2016 yılında dünyanın lider OTA'sı iken Booking.com ise Avrupa'nın liderleridir. Ayrıca, Expedia ABD pazarında önemli bir rol oynamaktadır. Pazar kontrolünün\%75'ine hâkimdir. Priceline Group ve Expedia dünyanın en büyük, egemen olanlarıdır (Morales, 2017: 13). 
Booking.com, Airbnb gibi otel listeleyen platformlar, sektördeki büyüyen platformizasyonun önde gelen örnekleridir (Gyodi, 2017: 2-3). Aynı kaynakta belirtildiği gibi, iki taraf arasında sosyal etkileşime gerek kalmadan, her işlemden belli bir komisyon oraniyla tahsilat gerçekleşmektedir. Platform otel/tesis (sağlayıcı) tarafından finanse edilmekte, müşteriler platform için bir komisyon ödememektedir. Ürün/hizmetlerin otelin web sitesi aracilığıyla dağıtılmasına doğrudan dağıtım denmektedir Doğrudan dağıtım, "tedarikçinin, müşteri değer zinciri içindeki tüm kaynaklara sahip olduğu ve yönettiği bir yapı" anlamına gelir (Dent, 2011: 11). Dağıtımın bir OTA vasıtasıyla olması ise tek kademe/aşamalı bir dağıtım şeklidir" (Dent, 2011: 11-12). Gerçekte ürün ve hizmetlerin otelin kendi web sitesinde OTA'dan daha ucuz olduğuna inanılmaktadır. Bunun da doğrudan dağıtım kanalı için bir avantaj olduğuna işaret edilmektedir (Morales, 2017: 10). Öyleyse çevrimiçi aracıları bu kadar cazip kılan nedir sorusuna cevap olarak, yukarıda pek çok kez vurgulandığı gibi, tüketicinin geniş çapta bilgi edinme ve karşılaştırma yapabilme ihtiyacına yönelik sunulan hizmet anlayışı verilebilir. Günümüzde farklı mecralardaki yaptığı reklam çalışmalarından şahit olunduğu gibi, birçok platform, internet kullanımında zaman ve para tasarrufu vurgusuyla potansiyel talebi kendi sitelerine yönlendirmeye çabalamakta ve böylece gerçekleşen satışlardan komisyon gelirlerini daha da artırmayı amaçlamaktadır.

Netice olarak, otel markalarına karşın, kendilerine en uygun konaklama tercihini sunan "OTA markalarının seyahat edenler tarafından çok iyi biliniyor ve tanınıyor olması, otellerin içinde olduğu bir gerçek ve aşılması gereken bir engeldir (Softinn, 2017). Çünkü yapılan her otel rezervasyonu için komisyon ödenmesi, otellerin daha düşük kâr marjı ile çalışması demektir (Rondeau, 2016). OTA'ların yüksek komisyon almakta olduklarına ve böylece işletmelerinin kar oranlarını azaltmakta olduğuna ilişkin yapılmış araştırmalara rastlamak mümkündür (Fox, 2014; Weiss, 2014).

\section{ÇALIŞMANIN AMACI}

OTA sektörü, çevrimiçi direkt dağıtımda büyük bir engelleyici durumundadır. Online sistemler üzerinden yapılan erken rezervasyonlar dahi artarken klasik acentalar üzerinden yapılan azalmaktadır. Google, Facebook, TripAdvisor, Trivago gibi metasearch siteleri ve Airbnb gibi diğer aracıların da ortaya çıkmış olması otel sektörü dağıtım ortamını daha da karmaşık hale getirmiştir. Kuşkusuz OTA'lar seyahat edenler için rezervasyonları kolaylaştırmaktadır. Buna bağlı olarak tüketiciler otellerin web sitelerinden rezervasyon yapmaya çok fazla ihtiyaç duymamaktadır. Sadece meta aramanın ötesinde, bazı OTA web siteleri artık kendilerini toptan satış yapacakları "çevrimiçi pazarlar" olarak konumlandırmaya dahi başlamıştır.

Çevrimiçi dağıtım alanı her zaman gelişen bir alandır. Yeni oyuncular/katılımcılar pazarın dinamiklerini zorlaştırmaya devam edeceklerdir. Otelciler, oda satmak için aracılarla çalışmaya devam ederken, dağıtımlarını kontrol etmede stratejik bir zorluk ile sürekli karşı karşıya olacaklardır.

Günümüzün rekabetçi piyasasında otel işletmeleri, çevrimiçi konuk için rekabet etmeleri gereken yerlerde, veri toplamak ve analiz etmek için teknolojiyi etkin bir şekilde kullanmak, istihbaratlar elde etmek ve daha aktif dağıtım yapmak için otel ekipleriyle daha yakın iş birliği içinde çalışmak durumundadır. Direkt fiyatın daima en iyi olmasını sağlamalıdır. Bu yaklaşım ancak otelin kar/zarar tablosunda çok olumlu bir etki yapacaktır. 
Platformlara ödenen yüksek komisyonlar sektör içinde yüksek sesle dile getirilen yakınmalar arasındadır. Oteller önemli bir sorun ile karşı karşıyadır. Bu nedenle doğrudan otel rezervasyon istatistiklerini iyileştirmek için zorlukların üstesinden gelmek, sürdürülebilir çözümler üretmek kritik öneme sahiptir.

$\mathrm{Bu}$ çalışma bilgi teknolojileri ve internetin geldiği nokta, birey ve işletmelere sağladığı kolaylaştırıcı katkılardan hareketle, bilgiye erişimden iletişimine ve satın alma süreçlerine kadar pek çok boyutta aracısız rezervasyon üzerine öneriler geliştirmeyi amaçlamakta, bunu yaparken tüketici arama davranışlarından teknik oluşum ve yapılanmalara kadar pek çok farklı boyutlara odaklanmaktadir.

\section{YÖNTEM}

Potansiyel tüketicilerin konaklama arama ve satın alma davranışlarını anlamak ve OTA'ların internetteki satış hakimiyetlerine dikkat çekmek amacıyla odak grup görüşmesi yöntemine başvurulmuştur. Yakın tarihli çalışmalardan Yılmaz ve Oğuz'un (2011) araştırmasında belirtildiği gibi, odak grup görüşmelerinin amacı, belirlenen bir konu hakkında katılımcıların bakıs, açılarına, yașantılarına, ilgilerine, deneyimlerine, eğ̈limlerine, düs,üncelerine, algılarına, duygularına, tutum ve alıs,kanlıklarına dair derinlemesine, detaylı ve çok boyutlu nitel bilgi edinmektir. Odak grup görüş̧melerinde önemli olan katılımcıların kendi görüsslerini özgürce ortaya koymalarını sağlayacak ortam olușturmaktır. Bu anlamda odak grup görüssmelerinin en önemli avantajı, grup içi etkileşimin ve grup dinamiginin bir sonucu olarak yeni ve farklı fikirlerin ortaya çımasıdır (Yılmaz ve Oğuz, 2011: 98).

Değerlerin daha doğru ve güvenilir çıkması için bu yöntem, sık seyahat eden ve dolayısıyla konaklama/otel arama davranışında sık bulunan akademisyenlere uygulanmıştır. Anadolu Üniversitesi, İletişim Bilimleri ve Turizm Fakültesinde görev yapan karma 10 (5 Erkek, 5 Kadın) akademik personel ile görüşülerek önceden hazırlanan sorular sorulup, bireylerin konaklama hizmeti satın alırkenki davranışları tespit edilmeye çalışılmıştır.

Araştırmada kullanılacak veri toplama aracının geliştirilmesi sürecinde ilk olarak, 3 kişiyle, potansiyel müşterilerin doğrudan otellerle etkileşimde olamama nedenlerine odaklanarak "odak grup görüşmesi" yapılmıştır. Böylece tüketicilerin konaklama arama ve satın alma davranışlarını anlamak ve OTA'ların internetteki hakimiyetlerine dikkat çekmek amacıyla araştırmacılar tarafından geliştirilmiş olan yarı yapılandırılmış görüşme formu hazırlanmıştır. Daha sonra bireylerle 5'er li odak grup görüşmeleri gerçekleştirilmiştir. Görüşmelerden elde edilen nitel veriler kayıt altına alınarak, içerik analizi yöntemiyle çözümlenmiştir.

Katılımcların demografik özellikleri yanında, başka bir ilde konaklama yapacak olmaları durumunda çevrimiçi arama davranışını araştırmaya yönelik üç soru yöneltilmiştir. Bunlar;

1- Direkt web tarayıcısını kullansanız otellerin listesini dökeceğini düşünerek adres çubuğuna (adres kutusu) yazacağınız web site adresi ne olurdu?

2- Google arama motorunu kullansanız hangi anahtar kelimelerle arama yapardınız?

3- Çevrimiçi otel satış siteleri/OTA kullanmak isteseniz hangilerini tercih ederdiniz? şeklinde sorular sorulmuştur.

Bilindiği gibi, odak grup görüşmelerinde çözümlemeler nicel çalışmalara göre daha az yapılandırılmış, daha çok açımlayıcıdır. Sayısallaştırma kabul gören bir yöntem değildir. Nitel bir veri toplama yöntemi olan odak grup görüşmelerinde genelleme yapmak 
düşünülmediğinden, sayısallaştırmaya da gerek bulunmamaktadır. Bu nedenle sonuçları verirken yüzde, frekans ya da istatistiksel testlere ya da tablolara gerek yoktur.

Sonuç olarak, bu çalışmada odak grup görüşmesinin raporlaştırılmasında sayılar değerlerden önce katılımcıların ne söylediği önemsenmiş ve görüşme neticesinde ortaya çıkan farklılıkların ortaya konulmaya çalışılmıştır.

\section{BULGULAR}

Seyahatten önce arama yaparken kullanılan internet adresi isimlerini/tercihlerini belirlemek için yöneltilen "Direkt web browser/tarayıcısı kullansanız otellerin listesini dökeceğini düşünerek adres çubuğuna yazacağınız web site adresi ne olurdu?" sorusuna ağırlıklı olarak google.com adresinin verildiği tespit edilmiştir. Aşağıdaki Tablo 1 incelendiğinde kişilerin yarısının kafasında bir OTA tercihi bulunmamaktadır. Metasearch platformu olarak Google'a başvurdukları anlaşılmaktadır. Öyleyse onlar için Google yönlendirici olmaktadır. Bu kesime görünür olabilmek için Google da iyi konumlanmak gerekecektir. Diğer taraftan, adres çubuğuna yazılabilir olmak için ise en az tabloda veriler diğer adresler kadar tanınıor, biliniyor ve güvenilir olmak gerekecektir.

Tablo 1. Browser ile Seyahat Ararken Kullanilan Adres Tercihleri

\begin{tabular}{|l|l|l|l|l|l|l|l|l|l|l|}
\hline KATILIMCILAR & $\mathrm{E} 1$ & $\mathrm{E} 2$ & $\mathrm{E} 3$ & $\mathrm{E} 4$ & $\mathrm{E} 5$ & $\mathrm{~K} 1$ & $\mathrm{~K} 2$ & $\mathrm{~K} 3$ & $\mathrm{~K} 4$ & $\mathrm{~K} 5$ \\
\hline google.com & $\mathrm{x}$ & $\mathrm{x}$ & & & & & $\mathrm{x}$ & $\mathrm{x}$ & $\mathrm{x}$ & \\
\hline booking.com & & & $\mathrm{x}$ & & & & & & & $\mathrm{x}$ \\
\hline hotels.com & & & & $\mathrm{x}$ & & & & & & \\
\hline trivago.com & & & & & $\mathrm{x}$ & $\mathrm{x}$ & & & & \\
\hline
\end{tabular}

Seyahatten önce arama yaparken arama motorunda kullanılan kelime tercihlerini belirlemek için yöneltilen "Google arama motorunu kullansaniz hangi anahtar kelimelerle arama yapardını?" sorusuna, Tabloda görüleceği gibi, ağırlıklı olarak şehir adı ve "otelleri" şeklinde bir kelime grubunun yazıldığı anlaşılmıştır. Bu cevabı veren katılımcılara neden bu kelimeleri tercih ettikleri, otel veya konaklama gibi kelimeleri tercih etmedikleri sorulmuştur. Cevaplardaki ortak nokta, akla ilk gelenin bu olduğu, böyle akılda kalıcı bir site altında otellerin bulunabileceği, iyelik ekli halinin bir site adı olabileceği söylenmiştir. Bu aşamada internet alan adı uzantısına ilişkin bir soru yöneltilmediğinden, kelime gurubunu internet adresi şeklinde (alan adı uzantısı ile) yazarak arama yaparım diyenler de olmuş ancak, sınırlılıklar çerçevesinde ayrı bir yoruma tabi tutulmadan bir sonraki soruya geçilmiştir.

Tablo 2. Arama motoru ile Seyahat Ararken Kullanılan Kelime Tercihleri

\begin{tabular}{|l|l|l|l|l|l|l|l|l|l|l|}
\hline KATILIMCILAR & E1 & E2 & E3 & E4 & E5 & K1 & K2 & K3 & K4 & K5 \\
\hline Ankara konaklama & $\mathrm{x}$ & & & & & & & & & \\
\hline Ankara otelleri & & $\mathrm{x}$ & $\mathrm{x}$ & $\mathrm{x}$ & & $\mathrm{x}$ & & $\mathrm{x}$ & & $\mathrm{X}$ \\
\hline Ankara otelleri + konum & & & & & & & $\mathrm{x}$ & & $\mathrm{x}$ & \\
\hline Ankara otel & & & & & $\mathrm{x}$ & & & & & \\
\hline
\end{tabular}

OTA tercihlerini belirlemek için yöneltilen "Çevrimiçi otel satı̧s siteleri (Online Seyhat Acentası-OTA) kullanmak isteseniz hangilerini tercih ederdiniz?" soruya aşağıda görüldüğü gibi ağırlıklı olarak booking.com cevabı alınmıştır. (Araştırmanın yapıldığı tarihte Booking.com Türkiye'de aktif faaliyette olduğu için yantlara yer verilmiştir). Bunu trivago.com izlemektedir. OTA tercih etmem ve otellerin kendi sitelerini kullanırım diyenler ise azımsanmayacak orandadır. Bu oran \%20 olup iki cevapta kadınlar tarafından verilmiştir. Nedenleri sorulduğunda ise daha garantili 
ve güvenilir olması ve bir sorun ile karşılaşıldığında daha kolay muhatap bulunabileceği belirtilmiştir. Bu bulgu, platformlar ve internet tekniklerine olan güven ne kadar oluşmuş olsa da $\% 20^{\prime}$ lik gibi belli oranda bir kesimin hala muhatap bulma ve kontak halinde olma ihtiyacı hissettiğini ortaya koymaktadır. Dijital sistemler, bu oranı ciddiye alarak platform yapıları içinde telefon vb. diğer teknolojileri de barındıran etkileşimli yapıları da korumalıdır.

Tablo 3. Çevrimiçi Seyahat Acenta Tercihleri

\begin{tabular}{|l|l|l|l|l|l|l|l|l|l|l|}
\hline KATILIMCILAR & E1 & E2 & E3 & E4 & E5 & K1 & K2 & K3 & K4 & K5 \\
\hline Kendi siteleri & & & & & & $\mathrm{x}$ & & $\mathrm{x}$ & & \\
\hline booking.com & $\mathrm{x}$ & & $\mathrm{x}$ & & & & $\mathrm{x}$ & & $\mathrm{x}$ & \\
\hline hotels.com & & $\mathrm{x}$ & & & & & & & & \\
\hline trivago.com & & & & $\mathrm{x}$ & $\mathrm{x}$ & & & & & $\mathrm{x}$ \\
\hline
\end{tabular}

Netice olarak Google arama motorunda, bir ilde konaklama araması yaparken kullanılan anahtar kelimeler il adı ve "otelleri" şeklinde bir yapı göstermektedir. Tüketici çevrimiçi arama davranışına ilişkin elde edilen bu tespit, alan adı yatırımcıları, içerik geliştiricileri ve Arama Motoru Optimizasyonu sunan girişimcilere yol gösteren değerli bir bulgudur.

Ayrıca Google trends sitesinden elde edilerek yansıtılan aşağıdaki Grafik 1'den görüleceği gibi, örnek olarak seçilen Ankara ili için, "Ankara Otelleri" kelimeleriyle yoğun arama yapılan tarihler yaz aylarıdır. Aynı siteden elde edilen verilere göre, bu kelimeler ile yoğun arama yapan iller sırasıyla; Ankara, İstanbul, Mersin, Samsun ve Konya şeklindedir. Yurt içi/dışı olarak bakıldığında ise yapılan aramaların \%1'inin Almanya'dan, \%99'unun ise yurtiçi olduğu görülmektedir.

Sonuç olarak, platform sağlayıcıları başarılarını en üst düzeye çıkarmak için arama motorlarında konumlanma konusunda mükemmel olmak zorundadır. Bulgularda görüleceği gibi, bir il için otel araması yaparken, internet kullanıcılarının yarısı Google arama motorunu kullanmaya eğilimlidir. Oluşturulacak siteler arama motoru algoritmasına uygun olarak tasarlanmalı, ilk sayfa organik arama sonuçları içinde çıkabilmelidir. Google'ın ilk sayfasındaki reklam alanları da dâhil yapılacak reklam-tutundurma çabaları içinde olmak kaçınılmazdır.

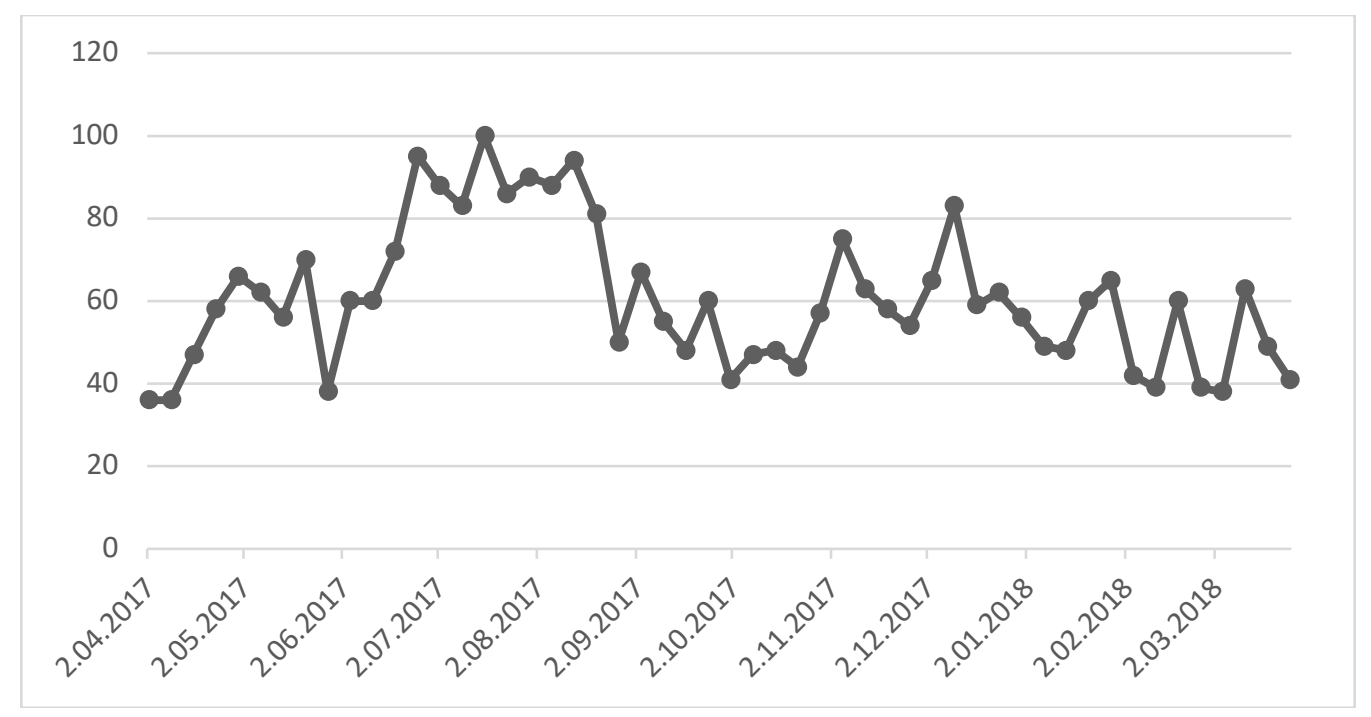

Grafik 1. Google Trends (Ankara Otelleri) Grafiği 
Çalışmadaki bulgular, Grafik 1'deki gibi, Ankara ili örneğinde bir analiz durumunu yansıtmaktadır. Çalışmanın sınırlılıkları açısından bir il'e ilişkin analizler ortaya konularak diğer destinasyon araştırmalarına model oluşturmak amaçlanmıştır. Kelime gurubu olarak "Ankara Otelleri" com uzantılı internet alan adının (ankaraotelleri.com) tescil edilip edilmediği ve ayrıca tescil edilmişse amacına uygun olarak kullanılıp kullanılmadığına bakılmıştır. Bu ismin tescil edildiği fakat amacina uygun kullanılmadığı̆ boş tutulduğu görülmüştür.

Türkiye'deki diğer tüm iller için bu sorgulama yapılmış, benzer internet alan adlarından sadece 3 ilin böyle bir adrese sahip olup amacına uygun olarak kullandığı anlaşılmıştır. Bunlar (canakkaleotelleri.com, eskisehirotelleri.com ve izmirotelleri.com) adresleridir. İllerden 16 'sina ait site isimleri tescil edilmiş fakat boş tutulurken, 13 ile ait ismin ikinci elde tekrar satışa sunulduğu, yani spekülatif amaçlı alındığı görülmüştür. İllerden 2'sine ait internet adresleri ise henüz tescil edilmemiş durumdadır. Ayrıca 44 ile ait internet adresleri ise farklı sektörden bir firma tarafından tescil edilmiş ve kendi faaliyetlerinin yer aldığı şirket sitesine yönlendirmiş durumdadir.

Diğer yandan turizm amaçlı aktif olarak kullanılan (canakkaleotelleri.com, eskisehirotelleri.com ve izmirotelleri.com) siteler/portalar, diğer bir ifadeyle platformlar için Google'da ilgili kelimeler kullanılarak (örnek, Eskişehir Otelleri) şeklinde arama yapılmıs, ancak ilk sayfada organik sıralama içinde yer alamadıkları tespit edilmiştir. Buna karşın ilk sayfada tüm OTA'ların yer aldığı görülmüştür.

Sonuç olarak, Literatürde çokça belirtildiği gibi, turizm platformlarının turizm ve konaklama pazarlamasında gerek işletmelere gerekse nihai tüketici ve turizm destinasyonlarına sağlayacağ 1 faydalar oldukça çeşitlidir. Bu faydalar bilgiye eşit erişimden tüketicilerin alternatifleri karşılaştırabilme olanaklarına ve bölgesel düzeyde kişiye özel ürün geliştirme olanağına kadar pek çok boyutta kendini göstermektedir (Sarı ve Kozak, 2005).

\section{SONUÇ VE ÖNERILER}

Bilgi teknolojileri ve internetin yaygınlaşmasıyla birlikte internet üzerinden yapılan konaklama satışları büyük bir hızla artış göstermiş, bunun farkında olan birçok seyahat acentası çevrimiçi platformlar oluşturmaya ve müşterilere buradan hizmet vermeye başlamıştır. Geleneksel dağıtım sisteminin hala kullanılmasına karşın internete dayalı dağıtım sisteminin hızla büyüdüğü ortadadır. Bunun nedenlerine yönelik yapılan çalışmalarda, "kullanıcı yorumları" ve "fiyat karşılaştırabilme" olanaklarına sahip olmak öne çıkmaktadır.

2000'li yılların başından itibaren ortaya çıkana dijital platformlar her zamankinden daha yaygın ve güçlü durumdalar. Bu nedenle ülke şirketlerinin bir platform sahibi olup olmadıklarına bakılmaksızın bir platform stratejisi geliştirmeyi düşünmeleri gerekir. Kuşkusuz tamamen yeni pazarlar yaratan, denklemin her iki tarafına da değer katan, daha güçlü dijital platformlar oluşturmak kaçınılmaz. Türkiye' de uygulanmasına ilişkin, mevzuat ve diğer nedenlerle üzerinde tartışmalar bulunsa da örneğin Uber, seyahat için ulaşım seçeneklerini ve iş bulma fırsatlarını artıran bir platform uygulaması olarak bugün için karşımızdadır. Keza benzer şekilde Airbnb' de gezginler için konaklama seçenekleri ve ev sahipleri için gelir fırsatları yaratan uygulamalardır. Bu tür uygulamaların kabul görmesi sahibinin pazar payını arttırırken, onların ağ etkisi aynı zamanda küresel ekonomileri dönüştürerek tüm katılanlar için de için de büyük bir değer yaratmaktadır. Küresel olarak, çoğu yönetici, dijital ekosistemlerin bilinen yöntemleri değiştirdiğinin, işleri geliştirmek için yeni ilişkilerden yararlanmak ve dijital ortaklar ağı 
geliştirmek yâda onlarla yaşamanın gerektiğinin farkındadır. Platform sağlayıcısı mı yoksa katılımcı mı olduğuna bakılmaksızın, tüm şirketler başarılarını en üst düzeye çıkarmak için ekosistemlerindeki platformların gücünden yararlanma konusunda mükemmel olmak zorundalar.

Günümüzde neredeyse tüm konaklama işletmeleri bir şekilde internet ortamında yer almakta, bir web sitesine sahip ve/veya dijital platformlarda (OTA, Metasearch, Search Engine) bulunmaktadır. Ne var ki OTA'ların web sitelerinde konumlanırken karışık ve kısıtlayıcı anlaşmalara imza atarak satışlar üzerinden önemli oranlarda komisyonlar ödemektedirler. Bu durum sektör tarafından her firsatta dile getirilen bir sorundur. Bugüne kadar konaklama tesislerinin aracısız ya da düşük aracı maliyetleriyle direkt satış başarısı arttırmaya yönelik yapılmış ne bir çalışma ne bir öneri bulunmamaktadır. Yapılan çalışmalar durumu ortaya koymaktan öteye gidememiştir.

Konaklama tesislerinin internette başka şekillerde konumlanabilme alternatifleri mevcuttur. Farklı yapılanmalar ve komisyonsuz farklı iş/gelir modelleri ile tüketicilerin tesis bilgilerine erişimleri karşılaştırma yapabilmeleri sağlanabilir. Böylece onların zaman ve para tasarruf amaçları da gerçekleşir. Örneğin ilk akla gelen; ankaraotelleri.com, ilrehberi.com, destinasyon.com, konaklamarehberi.com veya otelkarsilastir.com gibi isimler platform kooperatifçiliği (yani satışlardan komisyon verilmeyen) iş-gelir modeli yapılanması şeklinde OTA'ların benzeri olarak hayata geçirilebilir. Tüm oteller bir kooperatif gibi örgütlenebilir, üyelik modeliyle kendi platformlarını kolayca kurabilir.

Kolay ve akılda kalıcı pek çok internet adresi birileri tarafından tescil edilmiş olmakla birlikte bugün için kullanılmadan âtıl olarak durmaktadır. Ayrıca, "travel", "net" veya "org" gibi uzantılar da benzer amaçlarla kullanılabilir. Bu ara yüz sitelerden yönlendirilen trafikle otellerin kendi web siteleri de böylece daha fonksiyonel ve daha tanıtıcı tasarımlar olarak yeni bir fonksiyon, rol üstlenebilir.

Bulgularda görüleceği gibi, bir il için otel araması yaparken müşteriler çoklukla Google arama motorunu kullanmaya eğilimlidir. Oluşturulacak siteler arama motoru algoritmasına uygun olarak tasarlanmalı, organik arama sonuçları içinde çıkabilmelidir. Halen OTA'ların işgal ettiği Google'ın ilk sayfasındaki reklam alanları da dâhil yapılacak reklam-tutundurma çabalarıyla komisyonsuz iş modeline dayalı kooperatif platform siteleri hayata geçirilmelidir. Rol üstleniciler olarak, burada ilk akla gelen oyuncular sektörle en ilgili sivil toplum oluşumlarıdır. Onlarla birlikte Destinasyon Yönetim Organizasyonları (DMO) gibi resmi ya da yarı resmi kuruluşlar da işin içinde bulunmalıdır.

Platform ekosistemine değer katacak öneriler sunarken, ülkenin karşısında duran, uygun ortam ve kritik kitleyi oluşturma gibi iki kilit platform faktörü zorluklarına dikkat çekmek gerekir. Bu bağlamda, Türkiye, Platform Hazırlık Endeksi Sıralamasında yer alan 16 G20 ülkesinden 13. Sirada yer almakta ve 2020 yılına kadar bu konumda kalması beklenmektedir (Accenture, 2018). Dijital popülasyonun ve pazarın olgunluğunu büyüklüğe, tasarrufa, kültüre ve iş birliğine dayalı inovasyon ruhuna göre ölçen Accenture'ın Platform Hazırlık Endeksi, G20 ülkelerini dijital platformun benimsenmesi için uygun bir ortam yaratan etkenler konusunda karşılaştırma yapmaktadır. Yansıyan tabloya bakıldığında, Türkiye yüksek sayıda dijital platforma ev sahipliği yapmasına rağmen, hazırlık endeksindeki yeri açısından iyi bir görüntü vermemektedir. Fırsatlar çok olmakla birlikte, ülke için platform yolculuğu daha yeni başlayacak demektir. 
Netice olarak, tüm sektörler yeni normal için hazırlanmalı, gerekleri başarılı bir şekilde yerine getirmek için ihtiyaç duyduğu yeteneklere sahip olup olmadığına bakmalı ve işletme modelini ve kültürünü buna göre dönüştürmelidir. Kendisini, oynadığı rolden bağımsız olarak ekosistem gelişiminin kilit itici gücü olarak kabul etmeli, mevcut ve yeni ekosistem ortaklıklarını katılmaya istekli olmalıdır.

\section{KAYNAKÇA}

Accenture. (2018). South Africa: Winning with Digital Platforms, Gordon Institute of Business Science, University of Pretoria. https://www.accenture.com/t20180621T080542Z_w_zaen/_acnmedia/PDF-80/Accenture-Winning-Digital-Platforms.pdf, [Erişim Tarihi: 24.01.2019]

Algür S., Ömüris, E. ve Erdoğan C. (2006). An Evaluation on Online Reservation Web Sites, TurkKazakh International Tourism Conference, 1635-1648.

Algür, S. (2007). Elektronik Turizm: Internet Acentacılı̆̆ı Gelişimi, Tercih Nedenleri ve İleriye Yönelik Projeksiyonlar, Akdeniz Üniversitesi Yüksek Lisans Tezi. Antalya, https://www.academia.edu/1110411/ELEKTRONIK_TURIZM_INTERNET_ACENTACILIGI_G ELISIMI_TERCIH_NEDENLERI_ve_ILERIYE_Y\%C3\%96NELIK_PROJEKSIYONLAR, [Erişim Tarihi: 11.10.2018]

Ateş, U. ve Boz, M. (2015). Konaklama İşletmelerinin Web Sitelerinin Değerlendirilmesi: Çanakkale Örneği, JEBPIR, 1 (1), 2015, 63-84.

Bolton, R.N. and Drew, T.H. (1991). A Longitudinal Analysis of the Impact of Service Changes on Customer Attitudes. Journal of Marketing, 5, 1-9.

Bowen, J.T. and Shoemaker, S. (1998). Loyalty: A Strategic Commitment. Cornell Hotel $\mathcal{E}$ Restaurant Administration Quarterly, 39, 12-25.

Chingbiu, T. (2003). Disintermediation of Travel Agents in the Hotel Industry. International Journal of Hospitality Management, 22(4): 453-460

Cohen, N. (2017). Hotel Brand Websites, OTA's, Meta Search and Wholesalers: A Distribution Dilemma within the Industry, Boston Hospitality Review, Boston University School of Hospitality Administration, http://www.bu.edu/bhr/2017/06/07/hotel-ota-channel-distribution-dilemma/ [Erişim Tarihi: 22.01.2019]

Dent, J. (2011). Distribution channels: Understanding and managing channels to market. 2nd ed. Kogan Page Limited. Great Britain.

Emir, O. (2016). Otel İşletmelerinde Müşteri Memnuniyeti (Bă̆ımsız Devletler Topluluğundan Gelen Turistler Tarafindan Antalya'ya Yönelik Bir Değerlendirme. Detay Yayıncılık, Ankara.

ETTSA. (2010). Technology and Independent Distribution in the European Travel Industry, The European Technology \& Travel Services Association. http://www.ettsa.eu/uploads/documents/ETTSA_Study_2010_Single_Pages.pdf [Erişim Tarihi: 24.01.2019] 
European Union. (2017). Nestor Duch-Brown; The Competitive Landscape of Online Platforms, JRC Digital Economy Working Paper, 2017-04. https://ec.europa.eu/jrc/sites/jrcsh/files/jrc106299.pdf, [Erişim Tarihi: 28.01.2019]

Forbes. (2015). Competition is Shaking up the Online Travel Market. https://www.forbes.com/sites/greatspeculations/2015/01/05/competition-is-shaking-up theonline-travel-market/\#46a60d2430a8. [Erişim Tarihi: 08.01.2019]

Fox, L. (2014). Broken Down, How OTAs Are Eating Hotel Business. https://www.tnooz.com/article/OTAs-taking-hotelbusiness/ [Erişim Tarihi: 25.01.2019]

Garbarino, E. and Johnson, M.S. (1999). The Different Roles of Satisfaction, Trust, and Commitment in Customer Relationships, Journal of Marketing, 63, No. 2, 70-87.

Gyodi, K. (2017). Airbnb and Booking.com: Sharing Economy Competing Against Traditional Firms? Working Paper DELab UW । NO. 3. http://www.delab.uw.edu.pl/wpcontent/uploads/2017/09/WP_3_2017_K.Gyodi_.pdf, [Erişim Tarihi: 11.12.2018]

HL. (2016). Online Platforms and the Digital Single Market, 10th Report of Session 2015-16, https://publications.parliament.uk/pa/ld201516/ldselect/ldeucom/129/129.pdf, [Erişim Tarihi: 20.12.2018]

Kenney, M. and Zysman, J. (2016). The Rise of the Platform Economy, Issues, https://issues.org/the-rise-of-the-platform-economy/ [Erişim Tarihi: 29.01.2019]

Keskinkılıç M.; Ağca Y. ve Karaman E. (2016). İnternet ve Bilgi Sistemleri Kullanımının Turizm Dağıtım Kanallarına Etkisi Üzerine Bir Uygulama, İşletme Araştırmaları Dergisi, 8/4 (2016) 445-472.

Kracht, J. and Wang, Y. (2010). Examining the Tourism Distribution Channel: Evolution and Transformation, International Journal of Contemporary Hospitality Management, 22, 736-757.

Law, R.; Leung, R.; Lo, A.; Leung, D. and Fong, L.H. (2015). Distribution Channel in Hospitality and Tourism: Revisiting Disintermediation from the Perspectives of Hotels and Travel Agencies. Contemporary Hospitality Management, 27(3), 431- 452. doi:10.1108/IJCHM-11-2013-0498

Luebke, A. (2017). Top 5 Essential Tips to Increase Direct Booking, Tourism Review News, https://www.tourism-review.com/best-advice-to-boost-hotel-direct-booking-news5439, [Erişim Tarihi: 29.12.2018]

Marvel, M. (2016). The Hotel Distribution Report 2016. Hotel Analyst. http://hotelanalyst.co.uk/wpcontent/uploads/sites/2/2016/10/2016-HA-Hotel-Distributionreport-final-sample.pdf. [Erişim Tarihi: 14.12 .2018$]$

Morales T. (2017). Increasing Direct Booking in Hotels, Bachelor's Thesis Degree Programme in Tourism 2017. https://www.theseus.fi/bitstream/handle/10024/133719/Morales_Tara.pdf?sequence=1\&isAllow ed=y [Erişim Tarihi: 27.01.2019]

Morgan, R. M. and Hunt, S. D. (1994). The Commitment Theory of Relationship Marketing, 
Journal of Marketing, 58, 20-38.

Rondeau, D. (2016). What OTA Commissions are Costing You. http://blog.leonardo.com/otacommissions-costing/ [Erişim Tarihi: 19.12.2018]

Sarı Y., Kozak M. (2005). Turizm Pazarlamasında İnternetin Etkisi: Destinasyon Web Siteleri için Bir Model Önerisi, Akdeniz İ.I.B.F. Dergisi (9) s:248-271.

T.C. Ticaret Bakanlığı. (2018). Çevrimiçi Platformlar ve Şirketler. Sektör Haberleri. https://www.ticaret.gov.tr/blog/sektor-haberleri/cevrimici-platformlar-ve-sirketler [Erişim Tarihi: 14.01.2019]

Weiss, L. (2014). The Booking Battle: OTAs Break into the Loyalty Market, U.S News \& World ReportTravel: http://travel.usnews.com/features/The-BookingBattle-OTAs-Break-into-the-LoyaltyMarket/ [Erişim Tarihi: 24.01.2019]

Zengin B. and Şen L.M. (2006). Ethic Troubles Faced in Marketing of Travel Sector and Its Solution Suggestions (An Area Search in Istanbul). Turk-Kazakh International Tourism Conference, 976999. 